\title{
Graphene Based Sensors for Air Quality Monitoring - Preliminary Development Evaluation
}

\author{
Denise Machado ${ }^{1,2}$, Maria J. Hortigüela ${ }^{1}$, Gonzalo Otero-Irurueta ${ }^{1}$, Paula A.A.P. Marques ${ }^{1}$, \\ Ricardo Silva ${ }^{2}$, Rui F. Silva ${ }^{2}$ and Victor Neto," \\ ${ }^{1}$ Centre for Mechanical Technology and Automation (TEMA), Department of Mechanical engineering, University of Aveiro, 3810- \\ 193 Aveiro, Portugal \\ ${ }^{2}$ Aveiro Institute of Materials (CICECO), Department of Materials and Ceramic Engineering, University of Aveiro, 3810-193 \\ Aveiro, Portugal
}

\begin{abstract}
Indoor air pollution can induce adverse health effects on building occupants and pose a significant role in health worldwide. To avoid such effects, it is extremely important to monitor and control common indoor pollutants such as $\mathrm{CO}_{2}$, VOCs and relative humidity. Therefore, this work focuses on recent advances in the field of graphene-based gas sensors, emphasizing the use of modified graphene that broadly expands the range of nanomaterials sensors. Graphene films were grown on copper by chemical vapor deposition (CVD) and transferred to arbitrary substrates. After synthesis, the samples were functionalized with $\mathrm{Al}_{2} \mathrm{O}_{3}$ by $\mathrm{ALD}$ and characterized by a large set of experimental techniques such as XPS, Raman and SEM. The results demonstrated that graphene was successfully synthesized and transferred to $\mathrm{SiO}_{2}$, glass and polymer. As a proof-of-concept, ALD of $\mathrm{Al}_{2} \mathrm{O}_{3}$ was performed on the graphene surface to produce a graphene/metal oxide nanostructure towards the development of nanocomposites for gas sensing. From this perspective, a laboratory prototype device based in measuring the electrical properties of the graphene sample as a function of the gas absorption is under development.
\end{abstract}

Received on 02-04-2019 Accepted on 03-05-2019

Published on 14-10-2019

Keywords: Pollution, health, graphene; gas, sensors.

\section{INTRODUCTION}

Volatile organic compounds (VOCs), particulates (PM) of diverse sizes and microbial contaminants deteriorate indoor air quality (IAQ) and have subsequent effects on human health [1]. According to World Health Organization (WHO), it is estimated that, in 2016, household air pollution is estimated to have caused 3.8 million deaths from non-communicable diseases (including heart disease, stroke and cancer) and acute lower respiratory infections. In the same year, in Portugal, the mortality rate attributed to household and ambient air pollution was 9,8 per 100000 population [2]. For all these reasons, there is a need to control air quality so that the values do not exceed the limits imposed by the European Commission [3].

In the last years, devices that can measure and monitoring chemical-, physical- and biological- changes in the environment, with low cost, compact size, and low-power consumption have been developed under the form of sensors

"Centre for Mechanical Technology and Automation (TEMA), Department of Mechanical engineering, University of Aveiro, 3810-193 Aveiro, Portugal; E-mail: vneto@ua.pt
$[4,5]$. Sensors are devices that provides an output signal usable in response to a specific measure, such as observable chemical reactions between certain materials [6]. A gas sensor can be used to monitor potentially dangerous leaks and, if connected to an automatic control system, can be an advantage in detecting high concentrations of gas in a given environment $[7,8]$.

These can be classified according to their operating principle, namely metal-oxide semiconductor sensors (MOS) based on conductivity variation [9], amperometric sensors based on solids or liquid electrolytes [10], or optical sensors using fluorescence or absorption of light [11]. Metal oxides have been fabricated to monitor and detect VOCs for more than 50 years due to their semiconducting properties. Semiconducting metal oxides (SMOXs) are attractive for gas sensing applications since they are cheap, flexible to apply to different manufacturing methods and easy to use $[12,13]$.

They may also be divided into specifics sensors, which provide specific information regarding a target compound, or, non-specific, that provide a global response to one or several families of chemical species (In section 3 the sensors for air 
monitoring are presented in more detail) [14]. They play an important role in various fields of application such as environmental monitoring, industrial production and safety, and when integrated into measurement systems, they can detect changes that occur in the physical environment [14, $15]$.

Thus, due to its unique structure, uncommon chemical and physical properties, good conductivity and large specific surface area graphene based sensors performed well with good accuracy, rapidness, high sensitivity and selectivity, low detection limits, and long term stability [16]. Nowadays, it is clear that graphene is a very promising candidate to integrate sensors for IAQ monitoring [17, 18]. However, pristine graphene is chemically inert to be useful in the detection of gases. As such, an approach to increase its chemical activity is required, through functionalization [19].

The present work focuses on recent advances in the field of graphene-based gas sensors, emphasizing the use of modified graphene that broadly expands the range of nanomaterials sensors and intends to be the starting point for the development of a functional prototype of the chemical gas sensor with high sensitivity, from the modified graphene structures.

\section{Air Quality Requirements, Parameters and Assessment}

Indoor air pollutants may originate from a different range of sources such as combustion for heating, material deterioration and VOCs emitted from paints, varnishes and preservatives. In addition, insoluble nanoparticles as well as biological particles present in indoor air, can also affect human health through direct toxicity, immune and infectious mechanisms [20-30].

For air quality assessment, numerous indices were proposed. The first index was the "Pollutant Standard Index" (PSI), which was modified and replaced by the "Air Quality Index" (AQI), both of which were developed and introduced by the United States Environmental Protection Agency (US-EPA) [24]. In Europe, the Environment Directorate General of The European Commission ("DG Environment") has developed a legislation, which establishes health-based standards and objectives for a number of pollutants present in the air. These standards and objectives are summarized in the Table 1 [3]. As people spend a substantial part of their time on buildings, maintaining indoor air quality levels becomes a challenge to overcome. Thus, the use of sensors and the development of new materials, such as graphene-based sensors, allow these levels to be monitored and controlled.

Conventional analytical instruments can be use accurately to measure the concentration of pollutants inside the buildings, but are not practical because of their complexity, volume and emitted noise. In addition, most analyzes require sample preparation, so a real-time analysis is difficult to obtain [21, $25,26]$. Solid-state chemical sensors have been widely used, however, also their measurement accuracy is limited and

Table 1: Target and Limit Values for the Parameters of Indoor Air [3]

\begin{tabular}{|c|c|c|c|}
\hline Pollutant & Concentration & Averaging period & Legal nature \\
\hline \multirow{2}{*}{$\mathrm{PM}_{2.5}$} & \multirow{2}{*}{$25 \mu \mathrm{g} / \mathrm{m}^{3}$} & \multirow{2}{*}{1 year } & Target value to be met as of 1.1 .2010 \\
\hline & & & Limit value to be met as of 1.1 .2015 \\
\hline \multirow[t]{2}{*}{$\mathrm{SO}_{2}$} & $350 \mu \mathrm{g} / \mathrm{m}^{3}$ & 1 hour & Limit value to be met as of 1.1.2005 \\
\hline & $125 \mu \mathrm{g} / \mathrm{m}^{\circ}$ & & \\
\hline \multirow{2}{*}{$\mathrm{NO}_{2}$} & $200 \mu \mathrm{g} / \mathrm{m}^{3}$ & 1 hour & Limit value to be met as of 1.1 .2010 \\
\hline & $40 \mu \mathrm{g} / \mathrm{m}^{3}$ & 1 year & Limit value to be met as of 1.1 .2010 \\
\hline \multirow{2}{*}{$\mathrm{PM}_{10}$} & $50 \mu \mathrm{g} / \mathrm{m}^{3}$ & 24 hours & Limit value to be met as of 1.1 .2005 \\
\hline & $40 \mu \mathrm{g} / \mathrm{m}^{3}$ & 1 year & Limit value to be met as of 1.1 .2005 \\
\hline \multirow[b]{2}{*}{$\mathrm{Pb}$} & \multirow[b]{2}{*}{$0.5 \mu \mathrm{g} / \mathrm{m}^{3}$} & \multirow[b]{2}{*}{1 year } & Limit value to be met as of 1.1.2005 \\
\hline & & & $\begin{array}{l}\text { (or } 1.1 .2010 \text { in the immediate vicinity of specific, notified industrial } \\
\text { sources; and a } 1.0 \mu \mathrm{gg} / \mathrm{m}^{3} \text { limit value applied from } 1.1 .2005 \text { to } \\
\text { 31.12.2009) }\end{array}$ \\
\hline $\mathrm{CO}$ & $10 \mu \mathrm{g} / \mathrm{m}^{3}$ & $\begin{array}{l}\text { Maximum daily } 8 \\
\text { hours mean }\end{array}$ & Limit value to be met as of 1.1 .2005 \\
\hline Benzene & $5 \mu \mathrm{g} / \mathrm{m}^{3}$ & 1 year & Limit value to be met as of 1.1 .2010 \\
\hline Ozone & $120 \mu \mathrm{g} / \mathrm{m}^{3}$ & $\begin{array}{l}\text { Maximum daily } 8 \\
\text { hour mean }\end{array}$ & Target value to be met as of 1.1.2010 \\
\hline As & $6 \mathrm{ng} / \mathrm{m}^{3}$ & 1 year & Target value to be met as of 31.12 .2012 \\
\hline $\mathrm{Cd}$ & $5 \mathrm{ng} / \mathrm{m}^{3}$ & 1 year & Target value to be met as of 31.12 .2012 \\
\hline $\mathrm{Ni}$ & $20 \mathrm{ng} / \mathrm{m}^{3}$ & 1 year & Target value to be met as of 31.12 .2012 \\
\hline $\begin{array}{l}\text { Polycyclic Aromatic } \\
\text { Hydrocarbons }\end{array}$ & $\begin{array}{l}1 \mathrm{ng} / \mathrm{m}^{3} \text { (expressed as } \\
\text { concentration of } \\
\text { Benzo(a)pyrene) }\end{array}$ & 1 year & Target value to be met as of 31.12 .2012 \\
\hline
\end{tabular}


present a long-term stability problem [26]. Nanotechnology becomes to fill existing flaws by providing numerous opportunities for the development of the next generation gas detector with enhanced sensor performance such as high specificity, fast response, ultra-high sensitivity at extremely low concentrations and coverage, low power consumption, room temperature operation and good reversibility [26, 27].

\section{Graphene as a Sensor Device}

In the recent years, there has been a significant improvement in the construction of sensors with the incorporation of several nanomaterials, such as nanowires synthesized from metals, metal oxides, semiconductors, carbon nanotubes (CNT) and metal nanoparticles. Due to their conductive properties and high surface-to-volume ratio, nanomaterial thus contributing to the improvement of the analytical performance of such sensors [28-30]. One of the advantages of semiconductor gas sensors is the ability of easily combining the functions of a sensitive element and signal converter and control electronics in the same device, greatly simplifying the design [26, 31]. Nanostructures have a high surface-to-volume ratio, which is one of the most important characteristics of a material to be used for gas sensing and provides large active surface area for the interaction of gas molecules. This strongly favors the adsorption of gases on nanostructures and leads to highly sensitive sensors performance [32]. The most recent example of the application of new materials in this type of sensors are the studies of the use of graphene in sensors for air quality measurement [33, 34]. The two-dimensional (2D) materials have captured enormous interest after the first successful isolation of graphene in 2004 [28].

Graphene is an extremely diversified material, with exceptional characteristics that allows producing different materials with varied properties, leading to great technological advances in the most varied areas [16, 35]. Because silicon-based technology is close to the limit in terms of performance improvement, the electronic properties of graphene make it an excellent choice for the semiconductor industry $[33,36]$.

Compared to other materials graphene showed great potential for the construction of sensors. The combination of extraordinary properties makes graphene highly sensitive to changes of local environmental conditions, which is an important advantage in the sensing field, since all carbon atoms interact directly with the analyses, thus promoting higher sensitivity $[34,37]$. Fluctuations due to thermal movement of charges and defects limits the sensitivity of graphene. Each atom in the graphene is exposed to its environment, allowing it to sense individual events when a gas molecule attaches to graphene's surface [38]. The adsorbed molecules change the concentration in graphene, which leads to changes in resistance. The achieved sensitivity is due to the fact that graphene is an electronically low-noise material, which makes it a promising candidate for gas sensors [39].

The synthesis of graphene can be divided into two main categories: physical- and chemical methods as shown in

Table 2: Comparisons on Different Aspects of Methods for Graphene Synthesis [42]

\begin{tabular}{|c|c|c|c|c|}
\hline Synthesis methods & Precursors & Layer characters & Advantages & Disadvantages \\
\hline $\begin{array}{l}\text { Micromechanical } \\
\text { exfoliation }\end{array}$ & Graphite & $\begin{array}{l}\text { Single and multiple layers; } \\
\text { dimension ca. } 10 \mu \mathrm{m}\end{array}$ & $\begin{array}{c}\text { Simplicity; high quality; low } \\
\text { cost }\end{array}$ & Time-consuming; low yields \\
\hline $\begin{array}{l}\text { Chemical vapor } \\
\text { deposition }\end{array}$ & Hydrocarbon gases & $\begin{array}{l}\text { Single and multiple layers; } \\
\text { dimension ca. } 100 \mu \mathrm{m}\end{array}$ & $\begin{array}{l}\text { High quality; uniform; } \\
\text { largescale production }\end{array}$ & $\begin{array}{l}\text { High temperature }\left(1000^{\circ} \mathrm{C}\right) ; \\
\text { high cost; complicated process; low } \\
\text { yields }\end{array}$ \\
\hline $\begin{array}{l}\text { Epitaxial growth on } \\
\text { silicon } \\
\text { Carbide }\end{array}$ & SiC wafer & $\begin{array}{l}\text { Single and multiple layers; } \\
\text { dimension ca. } 50 \mu \mathrm{m}\end{array}$ & Uniform; high quality & $\begin{array}{l}\text { High cost; low yields; high } \\
\text { temperature; high vacuum; } \\
\text { single-crystal substrate }\end{array}$ \\
\hline Arc discharge & Graphite & $\begin{array}{l}\text { Single and multiple layers; } \\
\text { dimension hundreds of } \mathrm{nm} \text { ca. } \\
10 \mu \mathrm{m}\end{array}$ & $\begin{array}{l}\text { Low cost; easy doping; good } \\
\text { crystallinity; high thermal } \\
\text { stability }\end{array}$ & Non-uniform; impure \\
\hline $\begin{array}{l}\text { Chemical reduction of } \\
\text { GO }\end{array}$ & Graphite & $\begin{array}{c}\text { Single and multiple layers; } \\
\text { dimension tens of nm to ca. } 100 \\
\mu \mathrm{m}\end{array}$ & $\begin{array}{l}\text { High yields; low cost; } \\
\text { largescale production }\end{array}$ & Low quality \\
\hline $\begin{array}{l}\text { Intercalation of small } \\
\text { molecules } \\
\text { within graphite }\end{array}$ & Graphite & $\begin{array}{l}\text { Single and multiple layers; } \\
\text { dimension in tens of } \mu \mathrm{m}\end{array}$ & $\begin{array}{l}\text { Simplicity; benign; large-scale } \\
\text { production; low-cost }\end{array}$ & Time-consuming; impure \\
\hline Unzipping CNTs & CNTs & $\begin{array}{l}\text { Single and multiple layers; } \\
\text { dimension in several } \mu \mathrm{m}\end{array}$ & $\begin{array}{l}\text { Low cost; large-scale } \\
\text { production; high quality } \\
\text { (plasma etching) }\end{array}$ & Time-consuming; complicated process \\
\hline Electrochemical method & Graphite & $\begin{array}{l}\text { Single and multiple dimension; } \\
\text { hundreds of } \mathrm{nm} \text { to ca. } 10 \mu \mathrm{m}\end{array}$ & Low cost; high quality & Low yields \\
\hline Total organic synthesis & PAHs & $\begin{array}{c}\text { Single layer, dimension less } \\
\text { than } 20 \mathrm{~nm}\end{array}$ & $\begin{array}{l}\text { High quality precisely defined } \\
\text { structures }\end{array}$ & $\begin{array}{l}\text { High cost; limited size range; } \\
\text { complicated process }\end{array}$ \\
\hline
\end{tabular}


Table 2 and depends, among others, on the crystallinity, purity and desired size $[40,41]$.

The chemical vapor deposition (CVD) process is the most common method to grow graphene. It consists of breaking the bonds of the molecules of a gas subjected to high temperatures, so that the atoms coming from the gas are deposited on a certain substrate and the graphene films synthesized by this method can be transferred to other substrates, facilitating their integration into various materials $[30,43]$.

The deposition of high-quality graphene from CVD process is usually done onto various transition-metal substrates with copper $(\mathrm{Cu})$ as the most popular metal to produce homogeneous single layer graphene in large-area [44-46]. Copper is one of the best catalyst options because, even at $1000^{\circ} \mathrm{C}$, the solubility of carbon in copper is insignificant, so the carbon precursor forms graphene directly on copper surface during the growth step $[47,48]$.

\section{Functionalization of Graphene by Atomic Layer Deposition (ALD)}

The operating principle of graphene devices is similar to other solid-state sensors and is based on changes in their electrical conductivity due to gas molecules adsorbed on their surface, acting as donors or receivers $[49,50]$. Depending on the size relationship between a chemical species and material, these interfaces may be superficial when chemical and/or physical adsorption occurs, or volume interactions, when the chemical absorption passes through the active layer of the sensor (bulk effect) [51].

Figure 1 represents the schematic diagram of a back-gated graphene device on top of an arbitrary substrate during $\mathrm{NH}_{3}$ exposure with also a representation of current-biased measurement setup [51].

The natural properties of graphene and functionalized graphene, such as massless charged carriers, and the high interaction with gas molecules, make these one of the most efficient materials for detecting gases. The type of interactions between atoms and molecules of graphene differ from the weak interactions of van der Waals with the strong covalent bonds, which leads to an intense change in the conductivity of the graphene $[39,52,53]$.

Due to its high-quality crystal lattice, graphene has intrinsically low electrical noise and is capable of transmitting more charge fluctuations. Consequently, some additional electrons can create a noticeable change in the conductance of graphene. As all carbon atoms are located on the surface, small changes in the resistance of a graphene sheet, even if down the molecular level, are measurable [54] making graphene highly sensitive to any change in its surrounding environment $[39,52]$.

One of the techniques that allow the manufacture of atomicscale materials and components either as thin film or as nanoparticles with accuracy that cannot be achieved by current CVD techniques is atomic layer deposition (ALD). As matter of fact, ALD has proved to be a technique of choice for the coating of nanostructured carbon materials and it's based on self-limiting surface reactions separated in gas phases $[55,56]$. When two precursors $A$ and $B$ react on gas phases during the CVD deposition to produce a thin film on the surface of the substrate, the same precursors react separately in ALD with the substrate surface to produce a uniform coating. The principle is based on the splitting of the deposition reaction in two separated self-limiting reactions due to the deposition mechanism [57].

ALD of aluminum oxide $\left(\mathrm{Al}_{2} \mathrm{O}_{3}\right)$ using trimethylaluminum (TMA) and water as precursor were developed as a model for ALD system. The surface reaction during the ALD deposition mechanism has one of the highest ALD reaction enthalpies $[57,58]$.

Nowadays, with the down-scaling of semiconductor device dimensions, the requirement of nanotechnology has grown enormously and ALD has found new opportunities in microelectronics industry for the development of metal oxide semiconductor field effect transistors (MOSFETs) and highdensity memory devices with high-level integration $[59,60]$. In this way, ALD has proved to be suitable for the deposition of metal oxides. In general, metal oxide semiconductors are used as active layers in resistive sensors [61, 62].

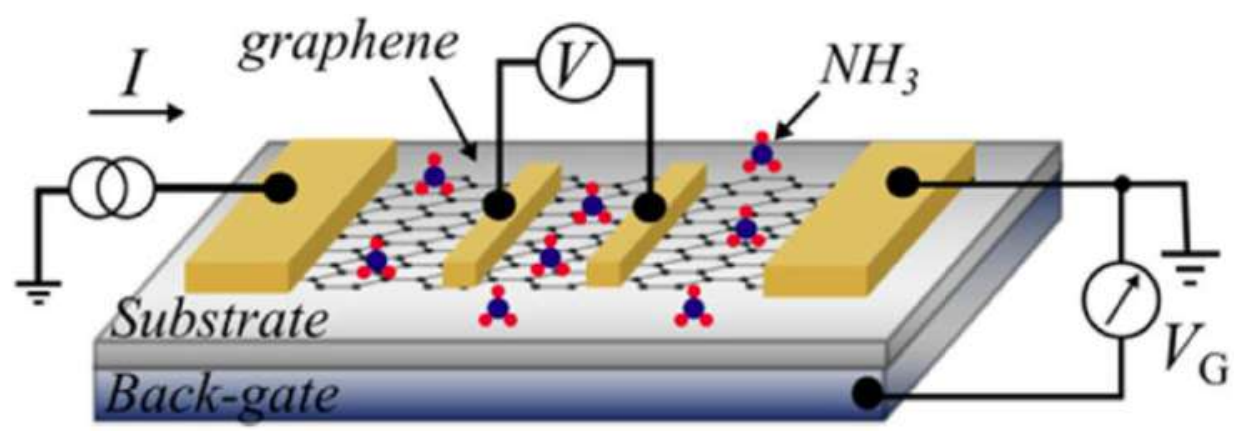

Figure 1: Schematic of a back-gated graphene device. [Reproduced with permission from ref [51], copyright @elsevier].

Authors: Cadore AR, Mania E, Alencar AB, et al. 
As a proof-of-concept, we synthesized CVD graphene on copper foils, in order to fabricate the platform for the sensing devices. The functionalization of CVD graphene via ALD is an interesting way to modify the surface properties of the asprepared graphene. As result, a nanostructure composed of graphene/metal oxide is obtained for detecting various gas species at room temperature.

\section{EXPERIMENTAL}

\section{Synthesis of Graphene by CVD}

Graphene samples were synthesized using CVD method at $950{ }^{\circ} \mathrm{C}$ and at a pressure of $4,67 \times 10^{4} \mathrm{~Pa}$. Copper with $25 \mu \mathrm{m}$ thickness was used as catalytic substrate. The heating step was started by increasing the furnace temperature from room temperature $\left(\approx 20{ }^{\circ} \mathrm{C}\right)$ to $950{ }^{\circ} \mathrm{C}$ under $117 \mathrm{sccm}$ (standard cubic centimeters per minute) $\mathrm{N}_{2}$ and $27 \mathrm{sccm} \mathrm{H}_{2}$ atmosphere. The annealing process was carried out under same conditions to remove oxide from the copper foil and to increase the grain size of $\mathrm{Cu}$. After keeping temperature at $950{ }^{\circ} \mathrm{C}$ for $64 \mathrm{~min}$, it was used an atmosphere rich in methane at a flow rate of $16 \mathrm{sccm}$ in order to grow graphene for $5 \mathrm{~min}$ and, finally, the sample was cooled down at natural velocity. The experimental parameters (temperature profile, gas composition and time) are shown in Figure 2.

\section{Transfer Process of Graphene}

Graphene films were removed from the copper foils by etching in a solution of iron chloride III $\left(\mathrm{FeCl}_{3}\right)$ with deionized water, as shown in Figure 3. Once the copper oxidation is complete, it is necessary to remove the floating graphene membrane so that it is subsequently transferred to an arbitrary substrate. The suspended films were transferred to deionized water (about $2 \mathrm{~min}$ ) to remove any residual copper etchant. Afterwards the graphene was transferred for $\mathrm{SiO}_{2} / \mathrm{Si}$
(Figure 3.1), glass (Figure 3.2) and polymer (Figure 3.3). From Figure 3 it is also possible to notice that the graphene was successfully removed from the copper foils and it can be seen as grey contrast on the top of the glass, for example (Figure 3.2). This transfer step is crucial, concerning the integration of the graphene in the sensor device fabrication process.

\section{ALD of $\mathrm{Al}_{2} \mathrm{O}_{3}$}

After the transfer step, the graphene functionalization was done with $\mathrm{Al}_{2} \mathrm{O}_{3}$ coating by $\mathrm{ALD}$ in home-made cross-flow reactor using a stop valve feature. ALD of $\mathrm{Al}_{2} \mathrm{O}_{3}$ process is based on the reaction between the water $\left(\mathrm{H}_{2} \mathrm{O}\right)$ and trimethylaluminum (TMA) precursors at $100^{\circ} \mathrm{C}$. To this end, the TMA and $\mathrm{H}_{2} \mathrm{O}$ were alternately pulsed on the graphene surface during deposition and the growth relies on two selflimiting surface reactions. Both precursors were kept at roomtemperature and pure nitrogen $\left(\mathrm{N}_{2}\right)$ was used as carrier and purge gas. To ensure higher exposure time of precursor gas over the graphene surface network, the stop valve mode was used. Several samples were prepared, with different number of ALD cycles.

The as-prepared nanostructures were characterized by a large set of experimental techniques such XPS, Raman, and SEM. In particular, the Raman scattering spectroscopy is remaining as a major technique in the study of graphene, providing a quick and simple characterization of the graphene structural defects accordingly to the literature [63]. SEM micrographs were obtained on a TM4000Plus microscope (Hitachi). The micrographs were recorder by a backscatter electrons detector for high contrast. Micro-Raman spectroscopy was performed using a Jobin Yvon (HORIBA) HR800 instrument, using a $530 \mathrm{~nm}$ laser wavelength as excitation source (Kimmon, IK series, Japan) and x100 objective ( $N A=0.9$, Olympus, Japan).

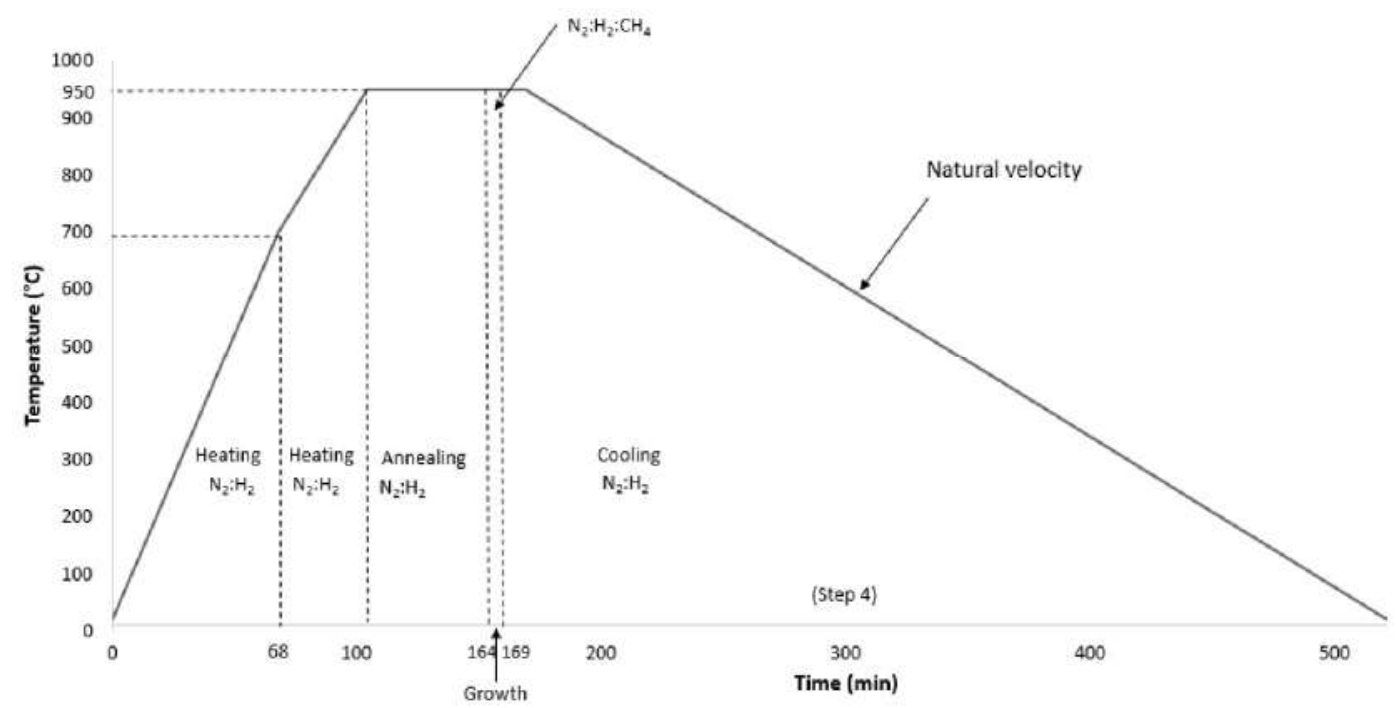

Figure 2: Optimized protocol of growth of graphene by CVD.

Authors: Denise Machado, Maria J. Hortigüela and Gonzalo Otero-Irurueta. 

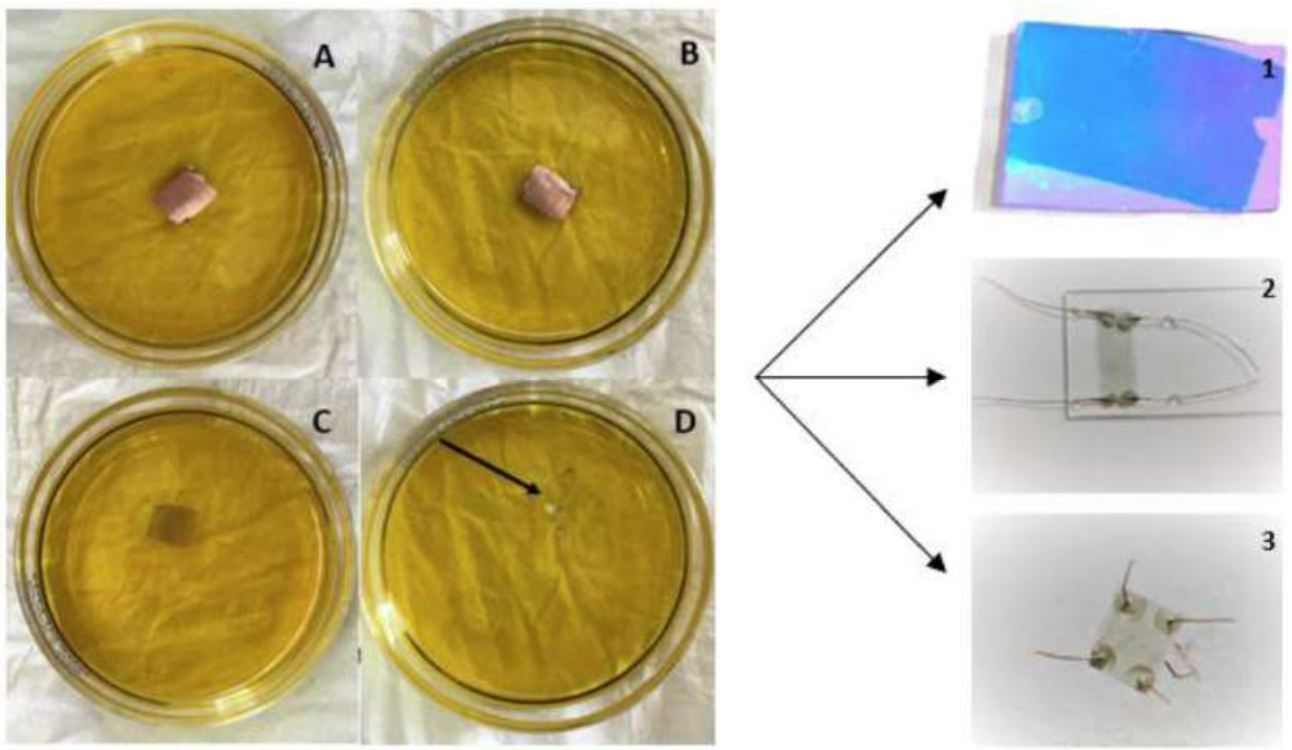

Figure 3: Transfer process of the graphene (from $\mathbf{A}$ to $\mathbf{D}$ ) to: 1) $\mathrm{SiO}_{2} / \mathrm{Si}, 2$ ) glass, 3) polymer.

Authors: Denise Machado, Maria J. Hortigüela and Gonzalo Otero-Irurueta.

High resolution X-ray photoelectron spectroscopy (XPS) was recorded in an ultra-high vacuum system (base pressure of $200 \mathrm{~Pa}$ ). The system combines a hemi-spherical electron energy analyzer (SPECS Phoibos 150), a delay-line detector and a monochromatic Al Ka X-ray source $(1486,74 \mathrm{eV})$. The spectra were acquired at normal emission take-off angle and with a pass-energy of $20 \mathrm{eV}$.

\section{RESULTS AND DISCUSSION}

In Figure 4, it is possible to observe the differences between the Raman spectra of the as-prepared graphene (red line) and the functionalized graphene after 50 ALD cycles of $\mathrm{Al}_{2} \mathrm{O}_{3}$ (green line). Three important features were observed in the Raman spectra and they are common to both samples; Dband (around $1300 \mathrm{~cm}^{-1}$ ) is usually associated with the density of defects present in the graphene network, that is, the intensity of the $\mathrm{D}$ band is directly related to the concentration of defects. On the other hand, the G-band (around $1580 \mathrm{~cm}^{-1}$ ) is associated to the in-plane vibration of the $\mathrm{sp}^{2}$ carbon atoms. Finally the 2D-band (around $2700 \mathrm{~cm}^{-}$ $\left.{ }^{1}\right)$ results from a second-order process [41]. These results indicate high-quality graphene grown on $\mathrm{Cu}$ emphasized by the less pronounced presence of the $D$ band when compared with the other two bands ( $G$ and $2 \mathrm{D}$ bands). Most importantly, the ALD of $\mathrm{Al}_{2} \mathrm{O}_{3}$ does not affect the intrinsic properties of the graphene demonstrated by the similarities of the Raman measurements. This finding also suggests that the ALD is a non-destructive technique to functionalize this type of nanomaterials.

These modes are present in all graphene-based materials, however, their frequencies, intensities, and line widths are influenced by other factors, such as the number of graphene layers, extern doping or laser excitation energy.

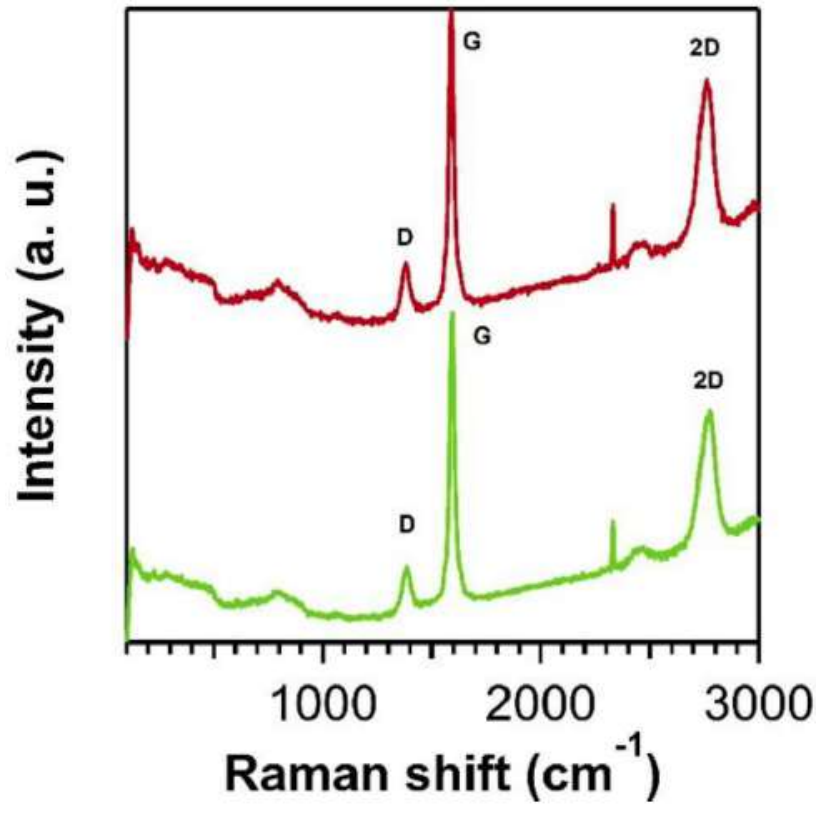

Figure 4: Raman spectra of the as-prepared graphene (red line) and after 50 ALD cycles with $\mathrm{Al}_{2} \mathrm{O}_{3}$ (green line). The Raman spectra was acquired at different points of the samples.

Author: Ricardo Silva.

XPS is a well-established experimental technique to understand the elemental composition and the chemical environment of the detected elements on surfaces. Figure 5A-B shows the comparison among high-resolution spectra of as grown (top) and transferred graphene (down), as it (red) and after $\mathrm{Al}_{2} \mathrm{O}_{3}$ functionalization by ALD (black). All the $\mathrm{C} 1 \mathrm{~s}$ spectra present asymmetric sharp peaks typical of graphene. The full width at half maximum (FWHM) of $C$ 1s from $\mathrm{Gr}$ on $\mathrm{Cu}$ and $\mathrm{Gr}$ transferred onto $\mathrm{SiO}_{2}$ have quite low values, 0,61 $\mathrm{eV}$ and $0,64 \mathrm{eV}$, respectively. This fact besides the absence 

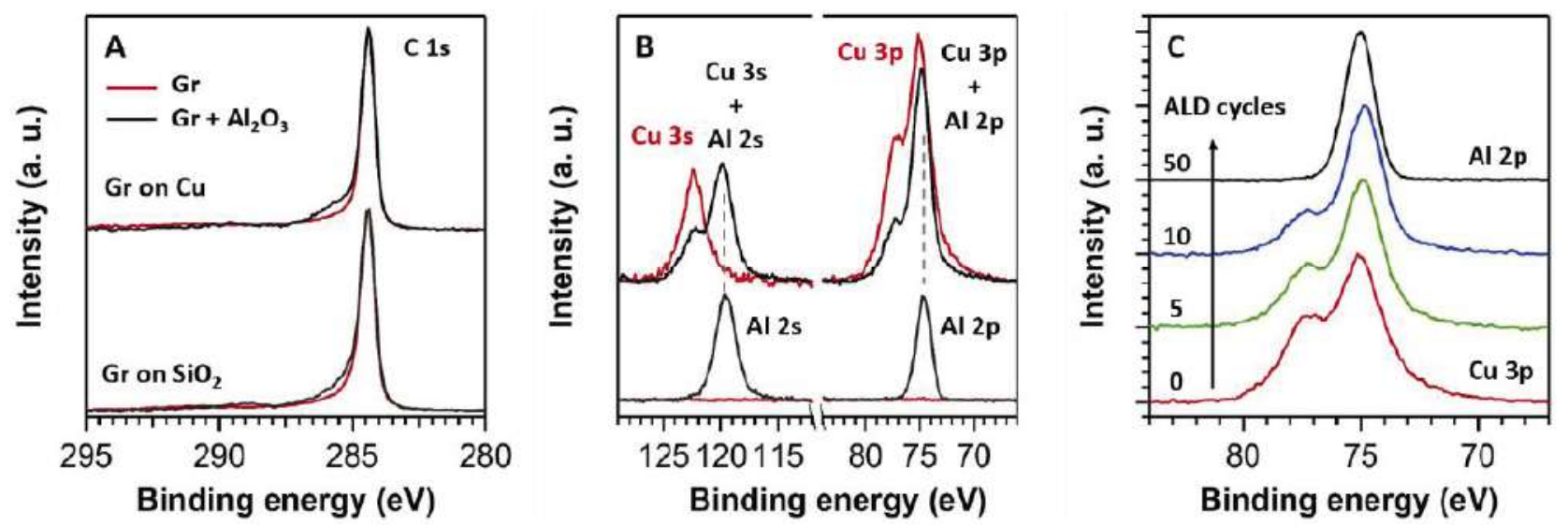

Figure 5: XPS spectra: A) normalized $\mathrm{C} 1 \mathrm{~s}$ peak, B) $\mathrm{Al} 2 \mathrm{~s} / \mathrm{Cu} 3 \mathrm{~s}$ and $\mathrm{Al} 2 \mathrm{p} / \mathrm{Cu} 3 \mathrm{p}$, from $\mathrm{Gr}$ on $\mathrm{Cu}$ (top) and $\mathrm{Gr}$ transferred to $\mathrm{SiO}_{2}(\mathrm{down})$ samples, as it (red) and after $\mathrm{Al}_{2} \mathrm{O}_{3}$ deposition by 10 cycles of ALD (black), C) Al2p/Cu3p region as a function of ALD cycles.

Authors: Maria J. Hortigüela and Gonzalo Otero-Irurueta.

of peaks at BEs related to carbon-oxygen species indicate a good quality $\mathrm{sp}^{2}$ carbon and a low damage of the structure due to the transfer process. After ALD functionalization FWHM of $C$ 1s peaks (black drawn) increase slightly, $0,63 \mathrm{eV}$ on $\mathrm{Cu}$ and $0,69 \mathrm{eV}$ on $\mathrm{SiO}_{2}$, and it appears a small shoulder at higher $\mathrm{BE}$ due to adventitious carbon contamination, more easily attached to $\mathrm{Al}_{2} \mathrm{O}_{3}$ than to $\mathrm{Gr}$.

Figure $5 \mathrm{~B}$ shows the energy regions corresponding to $\mathrm{Al} 2 \mathrm{p}$ and $\mathrm{Al} 2 \mathrm{~s}$ before (red) and after (black) 10 cycles of ALD functionalization. In the case of $\mathrm{Gr}$ on $\mathrm{SiO}_{2}$ (down) symmetric peaks show up centered at 74,6 eV and 119,6 eV confirming the successful deposition of aluminum oxide [64]. The case of $\mathrm{Gr}$ on $\mathrm{Cu}$ (top) is not so obvious due to the overlapping of $\mathrm{Al}$ $2 s$ and $\mathrm{Al} 2 p$ with $\mathrm{Cu} 3 s$ and $\mathrm{Cu} 3 p$ regions, respectively. Anyway, it is clear that the intensity of the component at the $\mathrm{BE}$ position of $\mathrm{Al}$ increase while the intensity coming from $\mathrm{Cu}$ peaks decrease.

ALD technique allows the control over the coverage of the sample. As it can be seen in Figure $5 \mathrm{C}$, the increment of ALD

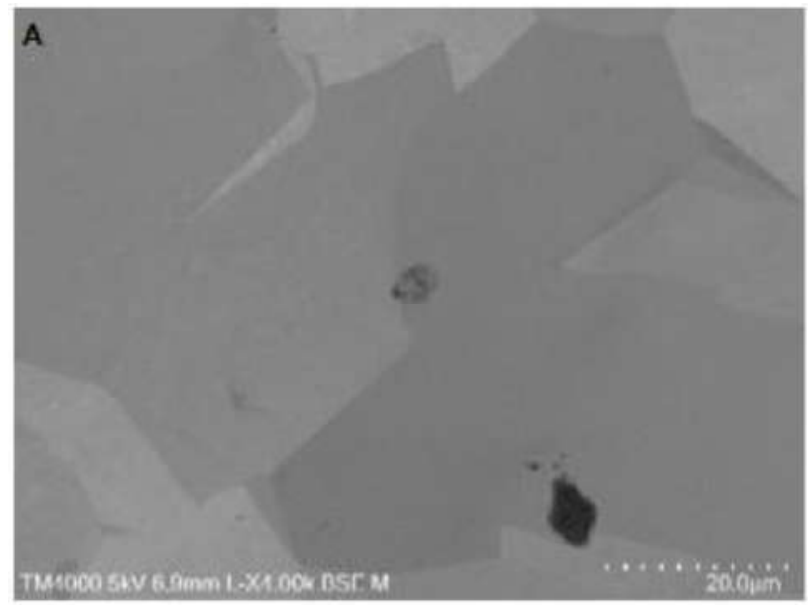

cycles increase progressively the coverage with aluminum oxide until a point (50 cycles) at which the $\mathrm{Cu}$ substrate cannot be detected by XPS.

Figure 6A-B shows the difference between SEM performed on graphene sample and on $\mathrm{SiO}_{2} / \mathrm{Si}$ with a growth time of 5 min. In Figure 6A can notice that the graphene film (darker contrast) are continuous, uniform and clean without noticeable particles, but grain boundaries, $\mathrm{Cu}$ surface steps, and wrinkles are observed. Figure $6 \mathrm{~B}$ shows that the graphene sheet has a much rougher surface, with some impurities and cracks. This roughness contrast can be explained as the topographic contrast that is the most frequent application of the SEM.

The results clearly demonstrate that graphene was successfully synthesized and transferred to the substrate.

Accordingly to the XPS studies, $\mathrm{Al}_{2} \mathrm{O}_{3}$ was successfully deposited on the graphene surface demonstrating the following two features: i) the graphene $2 \mathrm{D}$ nanomaterial is a suitable platform for the elaboration of nanostructures

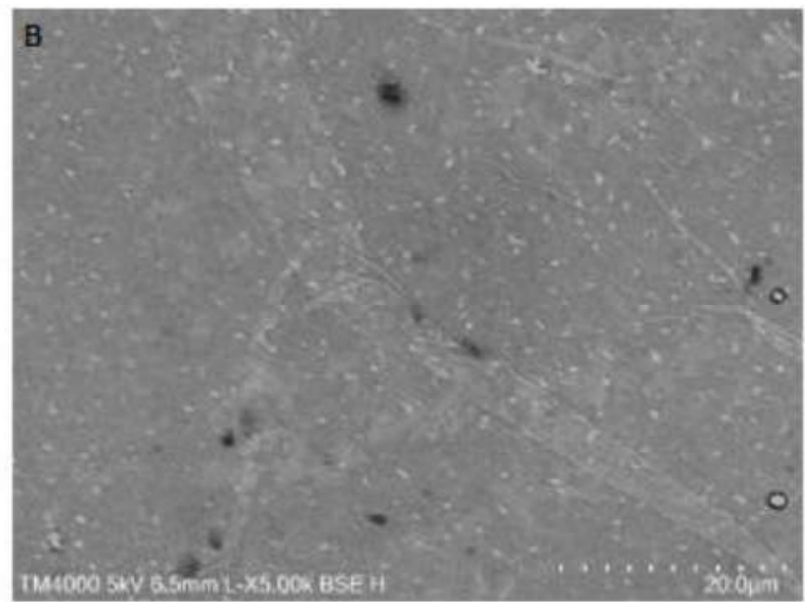

Figure 6: SEM image: A) Graphene in copper, B) Graphene transferred to $\mathrm{SiO}_{2} / \mathrm{Si}$.

Authors: Denise Machado, Maria J. Hortigüela and Gonzalo Otero-Irurueta. 


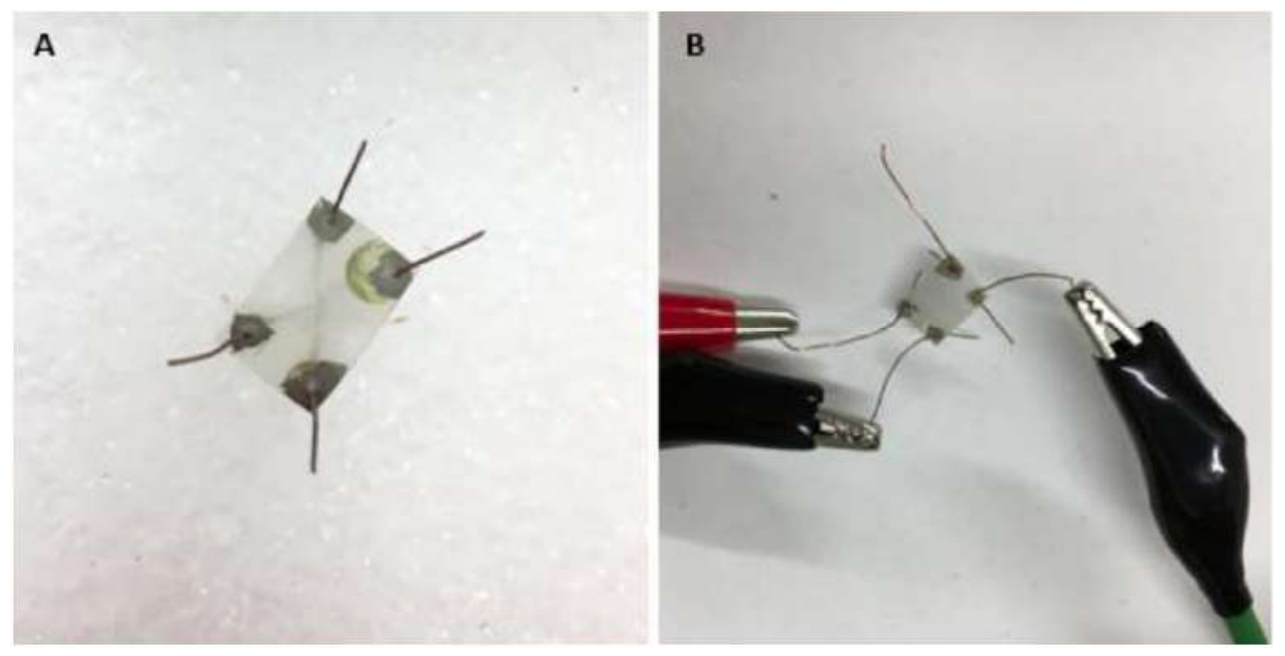

Figure 7: A) Experimental device, B) the connection with three cables for the graphene sensor.

Authors: Maria J. Hortigüela and Gonzalo Otero-Irurueta.

comprised of graphene/metal oxide and ii) the ALD technique is a non-destructive approach for the graphene surface functionalization. The combination of these features provides the means to develop new nanocomposites for gas sensing applications.

From this perspective, a laboratory prototype device based on measuring electrical properties of the graphene sample as a function of the gas absorption is under development. The basic concept to create a system using a graphene layer to detect the presence of gases in the atmosphere is based on the fact that the graphene surface can absorb these gases and the gas particles will change its resistivity value. The first step was to create a suitable device to measure the resistance and its variation in a graphene layer. This must be cheap, affordable, easy to replicate and a flexible measuring system that can guarantee a good accuracy and low noise levels. Figures 7A shows our experimental device and 7B the connections with three cables for the graphene sensor to detect $\mathrm{CO}_{2}$ in the atmosphere. In order to create a sensor, it is important to supply the graphene layer with very low currents and voltages to avoid burning or damaging the sensor.

The measuring system (Figure 8) consists of a chip-board to provide the desired current and voltage signal, and hardware to connect the $\mathrm{I} / \mathrm{O}$ of the board with the graphene sensor. The board chosen is a Cypress CY8CKIT-059 PSoC $® 5$ LP that has been programmed using the PSOC Creator 4.2 software. To reduce the noise, a real low-pass filter was built in the electric circuit on the bread-board, connecting a capacitor between the voltage output of the sensor and the ground. A led was also added in the circuit to signal the presence of $\mathrm{CO}_{2}$ in case the resistance value was going under a minimum threshold.

The possible solutions initially considered for the measurement hardware system were a four-points probe and a Wheatstone bridge architecture. The four-points probe is commonly used to measure sheet resistance of thin films,

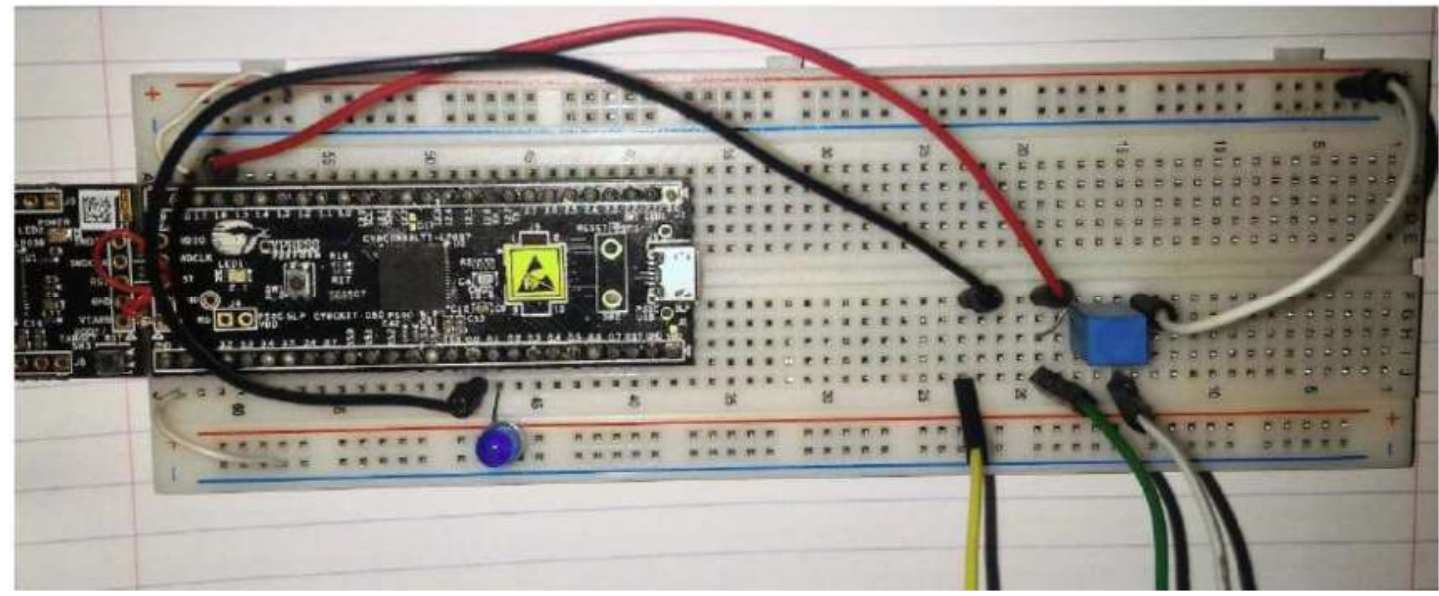

Figure 8: The bread-board integrating the controller-board and the electric circuit.

Author: Marco Machesi. 
Table 3: Experimental Sensors Characteristics

\begin{tabular}{|c|c|c|}
\hline Substrate & Dimensions & Connection \\
\hline \hline Glass (sensor 1) & $5 \mathrm{~mm} \times 20 \mathrm{~mm}$ & \multirow{2}{*}{ Copper wire and silver paint } \\
\hline Thermal release tape (sensor 2) & $7 \mathrm{~mm} \times 6 \mathrm{~mm}$ & \\
\hline
\end{tabular}

particularly semiconductor thin films. An advantage for accurate measurement of low resistance values is the separation of current and voltage electrodes that eliminate the lead and contact existence from the measurement. Because, at this point it is not relevant to know with high accuracy the absolute value of the resistance but it is important to detect with low ratio noise/signal the resistivity variation of the graphene sample, the solution adopted was a simple three cables connection to the sensor (I+, I- and ground), as shown in Figure $\mathbf{7 b}$. This method is easy to build, gives good results, is portable and cheap.

As we have demonstrated before, graphene was transferred to three substrates, however the experimental tests were made in glass (sensor 1) and plastic film (sensor 2). These features are explained in Table 3.

The perfect environment to perform the tests on the sensors would be a sealed box where it was possible to introduce specific amounts of $\mathrm{CO}_{2}$ or other gases, however, in this preliminary stage of the tests, they were performed in an open space (at the laboratory).

In order to analyze the results, the SerialChart application was used. It was connected to the same ComPort of the board and printed a graph of resistance value (blue) and voltage value (red) in real time (Figure 9). In brown is the current input. The tests were the same for both the sensors. The first step was to measure the resistivity under normal conditions and record their value. A glass bell was then placed on the top of the sensor and checked that no variations was presented on the resistivity. After that, the presence of $\mathrm{CO}_{2}$ and $\mathrm{H}_{2} \mathrm{O}$ vapor was tested. The tests were performed on different days and in two different laboratories. It was found that, due to the electrical sensitivity of the graphene, the resistivity value changed from one laboratory to the another and from one day to the next due to different atmospheric conditions. All the measurements were made with a current input of $5 \mu \mathrm{A}$. This value is high enough for a low noise signal rate and low enough not to degrade the samples. Because of the noise present in the system, values in an estimated range of $\pm 120 \Omega$ were considered.

Tests A and B were done using sensor 2 (graphene on thermal release tape) and test $C$ using sensor 1 (graphene on glass). Table 4 show the sample resistance under normal conditions when the $\mathrm{CO}_{2}$ bell is applied and with $\mathrm{CO}_{2}$ and $\mathrm{H}_{2} \mathrm{O}$ vapor.

Test $A$ was performed in the first laboratory and the sensor resistance under normal conditions was $9000( \pm 120) \Omega$. Applying the glass bell with $\mathrm{CO}_{2}$, the value decreased immediately and after 15 seconds reached the stable value of $7400( \pm 120) \Omega$, representing a decrease of $17,8 \%$. When the bell was removed, it took 4 minutes for the sensor to reach the initial value. Once the initial value was restored, the bell with $\mathrm{CO}_{2}$ and $\mathrm{H}_{2} \mathrm{O}$ vapor was placed, the resistance value started to increase and after 18 seconds reached the stable value of $10900( \pm 120) \Omega$. It increased approximately $21 \%$. When the bell was removed, more than 20 min were required to the sensor to reach the initial value.

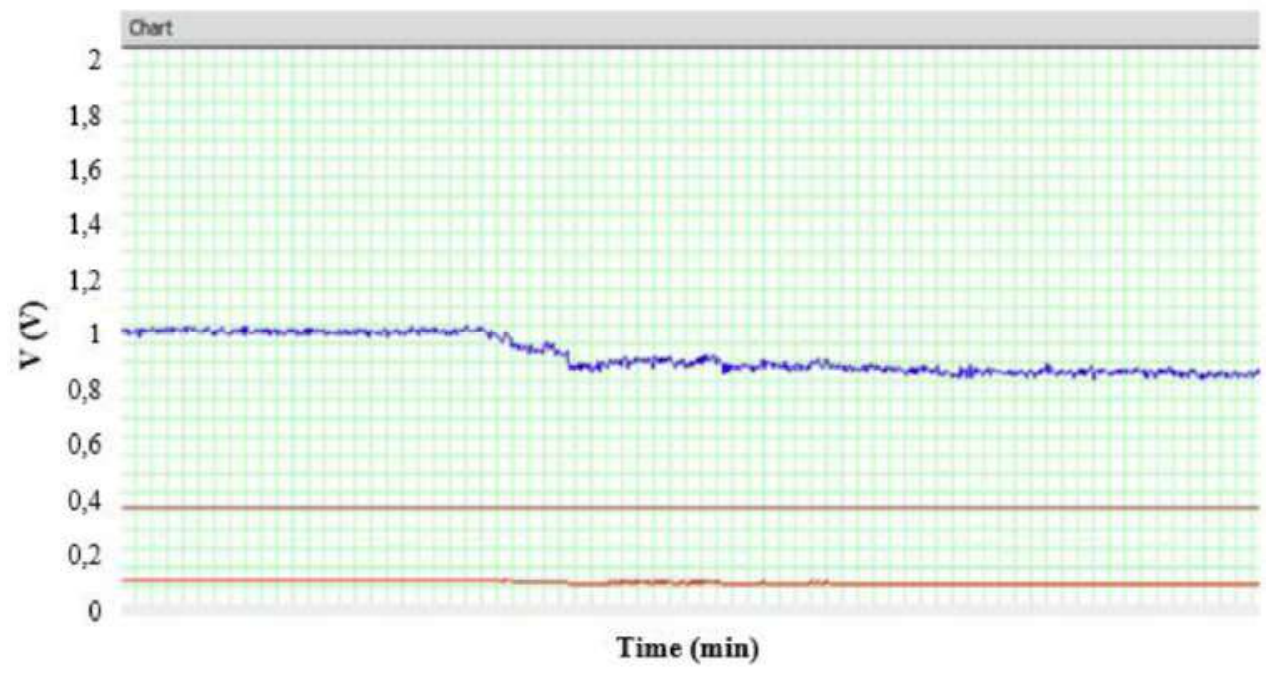

Figure 9: Chart print in the SerialChart program in real time.

Author: Marco Machesi. 
Table 4: Comparison between Sample Resistance in Normal Conditions, Applying $\mathrm{CO}_{2}$ and $\mathrm{CO}_{2}$ and $\mathrm{H}_{2} \mathrm{O}$ Vapor

\begin{tabular}{|c|c|c|c|}
\hline Test & $\begin{array}{c}\text { Resistance }( \pm 120 \Omega) \\
{[\Omega]}\end{array}$ & $\begin{array}{c}\mathbf{C O}_{2}( \pm 120 \Omega) \\
{[\Omega]}\end{array}$ & $\begin{array}{c}\mathbf{C O}_{2} \text { and } \mathrm{H}_{2} \mathrm{O} \text { vapor }( \pm 120 \Omega) \\
{[\Omega]}\end{array}$ \\
\hline \hline A & 9000 & 7400 & 10900 \\
\hline B & 8700 & 7600 & 10600 \\
\hline C & 3600 & 3200 & 4300 \\
\hline
\end{tabular}

Test B was done with the same sensor but in the second laboratory. The sensor resistance in normal conditions was $8700( \pm 120) \Omega$. Applying the bell with $\mathrm{CO}_{2}$ the value was decreasing and reached the normal stable value after 12 seconds. The value decreased by $12,6 \%$ to $7600( \pm 120) \Omega$. After the bell was removed, approximately $4 \mathrm{~min}$ were necessary to the sensor to reach the initial value. When the bell with $\mathrm{CO}_{2}$ and $\mathrm{H}_{2} \mathrm{O}$ vapor was placed, the value started to increase and after 18 seconds it reached the stable value of $10600( \pm 120) \Omega$, increasing approximately $22 \%$. Again, when the bell was removed, more than $20 \mathrm{~min}$ were necessary to the sensor to reach the initial value.

The last test (test $C$ ) was performed again in the first laboratory with sensor A (graphene on glass) with an initial resistance of $3600( \pm 120) \Omega$. Applying the bell with $\mathrm{CO}_{2}$ and after 12 seconds it reached the stable value of $3200( \pm 120)$ $\Omega$, decreasing approximately $11 \% .3 \mathrm{~min}$ after the bell was removed, the sensor reached the initial value. Once the initial value has been restored, the bell with $\mathrm{CO}_{2}$ and $\mathrm{H}_{2} \mathrm{O}$ vapor has been placed and the value increase immediately. After 20 seconds it reached the stable value of $4300( \pm 120) \Omega$, an increase of $19,4 \%$ After the bell was removed more than 15 minutes were necessary to the sensor to reach the initial value.

\section{CONCLUSION AND FUTURE WORK}

With ever-growing environmental concerns, the detection and monitoring of various gaseous species are of critical importance. Indoor air pollutants might be originated from a range of sources. Most of these pollutants, namely $\mathrm{CO}, \mathrm{CO}_{2}$, $\mathrm{NO}_{\mathrm{x}}, \mathrm{VOCs}, \mathrm{PM}_{10}, \mathrm{PM}_{2.5}$, relativity humidity and temperature are inhaled and affect human health. That way, the present paper reflects a preliminary study on the importance and the interest of the incorporation of modified graphene in sensors for gas monitoring, air quality and detection of potentially dangerous leaks.

Graphene has significant applications in electronics, presenting itself as a strong candidate in the replacement of silicon in future solid-state devices. However, there are barriers to be transposed, as is the case of the absence of an energy gap (bandwidth energy prohibited). Without the gap, you cannot turn semiconductor devices on and off. In this sense, it is highly desirable to introduce a banned energy band onto graphene in order to shape its transport properties. An adjustable band gap would then be desirable because it would allow great flexibility in design and optimization of such devices, particularly if such adjustment by applying a variable external electric field.

The results clearly demonstrate that graphene was successfully synthesized and transferred to the substrate and the successfully deposition of $\mathrm{Al}_{2} \mathrm{O}_{3}$ via ALD on the graphene surface and further demonstrating that the graphene surface functionalization is feasible. An easy way to improve the performance of the sensors presented will be by using insulated cables and better quality connections to reduce the noise present in the system. Although the tests were done in a non-optimal environment with multiple influencing factors and disturbances, it is possible to clearly detect the variations of gases in the air around the sensor, in particular $\mathrm{CO}_{2}$ and $\mathrm{H}_{2} \mathrm{O}$ vapor. These sensors cannot detect small variations of gas particles in the air but they are a starting point for further work toward this goal. From this perspective, a laboratory prototype device based on measuring electrical properties of the sample as a function of the gas absorption is under development. Also, as future work, additional research on the functionalization of graphene will be performed to improve the sensitivity and selectivity of the sensor for air pollutants such as for example VOCs, PM and CO. Finally, it should be noted that a method for the mass production of graphene has not yet been identified being also a future work to be considered.

\section{ACKNOWLEDGEMENTS}

This work is financed by Portugal 2020 through European Regional Development Fund (ERDF) in the frame of Operational Competitiveness and Internationalization Programmer $(\mathrm{POCl})$ in the scope of the project SGH-Smart Green Homes - POCI-01-0247-FEDER-07678.

Part of the research presented in this paper received support of the Portuguese Foundation for Science and Technology through TEMA strategic development project with reference UID/EMS/00481/2013 and TEMA Research Infrastructures project with reference CENTRO-01-0145-FEDER-022083, as well as from CICECO - Aveiro Institute of Materials project POCl-01-0145-FEDER-007679 (FCT Ref. UID /CTM /50011/2013), financed by national funds through the FCT/MEC and when appropriate co-financed by FEDER under the PT2020 Partnership Agreement. Authors acknowledge the contribution of Marco Machesi and Professor José Paulo Santos for the setup of the electrical measuring system. 


\section{REFERENCES}

[1] Wei W, Ramalho O, Mandin C. Indoor air quality requirements in green building certifications. Build and Environ 2015; 92: 10-9. https://doi.org/10.1016/i.buildenv.2015.03.035

[2] Ghebreyesus TA, Al-Ansary LA, Grove JT. World health statistics 2018. World Health Organization; 2018.

[3] Air Quality - Existing Legislation, E. Commission [Internet]. 2017. Available from: http://ec.europa.eu/environment/air/quality/existing_ leg.htm

[4] Arroyo P, Lozano J, Suárez JI, Herrero JL, Carmona P. Wireless Sensor Network for Air Quality Monitoring and Control. Chem Eng Trans 2016; 54: 217-22.

[5] Kataoka H, Ohashi Y, Mamiya T, et al. Indoor Air Monitoring of Volatile Organic Compounds and Evaluation of Their Emission from Various Building Materials and Common Products by Gas Chromatography-Mass Spectrometry. In: Advanced Gas Chromatography - Progress in Agricultural Biomedical and Industrial Applications, Dr. Mustafa Ali Mohd, editor. InTech 2010; p 161-84.

[6] Parks $\mathrm{H}$, Needham W, Rajaram S, et al. Semiconductor Manufacturing. In: The electrical engineering Handbook. Electronics, Power Electronics, Optoelectronics, Microwaves, Electromagneticas, and Radar. 3rd ed. Boca Raton: Taylor \& Francis Group, LLC 2006; p 64-132.

[7] Xiao Z, Kong LB, Ruan S, et al. Recent Development in Nanocarbon Materials for Gas Sensor Applications. Sens Actuators B Chem 2018; 274: $235-67$ https://doi.org/10.1016/..snb.2018.07.040

[8] Medvedeva E, Baranov A, Somov A. Design and investigation of thin film nanocomposite electrodes for electrochemical sensors. Sens Actuators B Chem 2016; 236: 858-64. https://doi.org/10.1016/j.snb.2016.02.104

[9] Hung CM, Thi D, Le T, Hieu N Van. On-chip growth of semiconductor metal oxide nanowires for gas sensors: A review. Journal of Science: Advanced Materials and Devices 2017; 2: 263-85.

https://doi.org/10.1016/i.jsamd.2017.07.009

[10] Ouyang Y, Wang X, Yu G, Song Z, Zhang X. Performance of Amperometric and Potentiometric Hydrogen Sensors. J Mater Sci Technol 2014; 30: 1160-65. https://doi.org/10.1016/j.jmst.2014.07.001

[11] Li C, Shi G. Carbon nanotube-based fluorescence sensors. J Photochem Photobiol C 2014; 19: 20-34 https://doi.org/10.1016/i.jphotochemrev.2013.10.005

[12] Barsan N, Koziej D, Weimar U. Metal oxide-based gas sensor research: How to?. Sens Actuators B Chem 2007; 121: 18-35. https://doi.org/10.1016/..snb.2006.09.047

[13] Kanan SM, El-kadri OM, Abu-yousef IA, Kanan MC. Semiconducting Metal Oxide Based Sensors for Selective Gas Pollutant Detection. Sensors 2009; 9: 8158-96. https://doi.org/10.3390/s91008158

[14] Caron A, Redon N, Thevenet F, Hanoune B, Coddeville P. Performances and limitations of electronic gas sensors to investigate an indoor air quality event. Build Environ 2016; 107: 19-28. https://doi.org/10.1016/j.buildenv.2016.07.006

[15] Ampuero S, Bosset JO. The electronic nose applied to dairy products: A review. Sens Actuators B Chem 2003; 94: 1-12. https://doi.org/10.1016/S0925-4005(03)00321-6

[16] Atta NF, Galal A, El-Ads EH. Graphene - A Platform for Sensors and Biosensors Applications. In: Biosensors - Micro and Nanoscale Applications. Intech 2015; p 37 - 84. https://doi.org/10.5772/60676

[17] Jiang W-S, Xin W, Xun S, et al. Reduced graphene oxide-based optical sensor for detecting specific protein. Sens Actuators B Chem 2017; 249: 142-48.

https://doi.org/10.1016/i.snb.2017.03.175

[18] Gutierrez F, Gonzalez-Dominguez JM, Ansón-Casaos A, et al. Singlewalled carbon nanotubes covalently functionalized with cysteine: A new alternative for the highly sensitive and selective $\mathrm{Cd}(\mathrm{II})$ quantification. Sens Actuators B Chem 2017; 249: 506-14. https://doi.org/10.1016/j.snb.2017.04.026

[19] Liu CS, Jia R, Ye XJ, Zeng Z. Non-hexagonal symmetry-induced functional $\mathrm{T}$ graphene for the detection of carbon monoxide. $\mathrm{J}$ Chem Phys 2013; 139: 1-7. https://doi.org/10.1063/1.4813528

[20] Kumar P, Skouloudis AN, Bell M, et al. Real-time sensors for indoor air monitoring and challenges ahead in deploying them to urban buildings. Sci Total Environ 2016; 560: 150-59. https://doi.org/10.1016/i.scitotenv.2016.04.032
[21] Mead MI, Popoola OAM, Stewart GB, et al The use of electrochemical sensors for monitoring urban air quality in low-cost, high-density networks. Atmos Environ 2013; 70: 186-203. https://doi.org/10.1016/j.atmosenv.2012.11.060

[22] Kumar P, Pirjola L, Ketzel M, Harrison RM. Nanoparticle emissions from 11 non-vehicle exhaust sources - A review. Atmos Environ 2013; 67: 252-77.

https://doi.org/10.1016/j.atmosenv.2012.11.011

[23] Wolkoff P. Indoor air pollutants in office environments: Assessment of comfort, heath, and performance. Int J Hyg Environ Health 2013; 216 : 371-94.

https://doi.org/10.1016/i.ijheh.2012.08.001

[24] U.S.EPA. Federal Register:rules and regulations. U.S. Environmental Protection Agency, Air quality index reporting. Fed Regist. 1999; 73 74932-43.

[25] Kumar $\mathrm{P}$, Morawska L, Martani $\mathrm{C}$, et al. The rise of low-cost sensing for managing air pollution in cities. Environ Int 2015; 75: 199-205. https://doi.org/10.1016/i.envint.2014.11.019

[26] Capone S, Forleo A, Francioso L, et al. Solid State Gas Sensors: State of the Art and Future Activities. Journal of optoelectronics and Advanced Materials 2004; 5: 1335-348. https://doi.org/10.1002/chin.200429283

[27] Varghese SS, Lonkar S, Singh KK, Swaminathan S, Abdala A Recent advances in graphene based gas sensors. Sens Actuators B Chem 2015; 218:160-83.

https://doi.org/10.1016/j.snb.2015.04.062

[28] Justino CIL, Gomes AR, Freitas AC, Duarte AC, Rocha-Santos TAP. Graphene based sensors and biosensors. Trends Analyt Chem 2017; 91: 53-66. https://doi.org/10.1016/j.trac.2017.04.003

[29] Bollella P, Fusco G, Tortolini C, et al. Beyond graphene: Electrochemical sensors and biosensors for biomarkers detection. Biosens Bioelectron 2017; 89: 152-66. https://doi.org/10.1016/j.bios.2016.03.068

[30] Wang T, Huang D, Yang Z, et al. A Review on Graphene-Based Gas/Vapor Sensors with Unique Properties and Potential Applications. Nano-Micro Lett 2016; 8: 95-119. https://doi.org/10.1007/s40820-015-0073-1

[31] Tricoli A, Righettoni M, Teleki A. Semiconductor Gas Sensors: Dry Synthesis and Application. Angew Chem Int Ed Engl 2010; 49: 7632 59 https://doi.org/10.1002/anie.200903801

[32] Jiménez-Cadena G, Riu J, Rius FX. Gas sensors based on nanostructured materials. Analyst 2007; 132: 1083-99. https://doi.org/10.1039/b704562

[33] Chaika AN, Aristov VY, Molodtsova OV. Graphene on cubic-SiC. Prog Mater Sci 2017; 89: 1-30. https://doi.org/10.1016/j.pmatsci.2017.04.010

[34] He Q, Wu S, Yin Z, Zhang H. Graphene-based electronic sensors. Chem Sci 2012; 3: 1764-72. https://doi.org/10.1039/c2sc20205k

[35] Kulkarni GS, Reddy K, Zhong Z, Fan X. Graphene nanoelectronic heterodyne sensor for rapid and sensitive vapour detection. Nat Commun 2014; 5: 1-7. https://doi.org/10.1038/ncomms5376

[36] Ghany NA, Elsherif SA, Handal HT. Revolution of Graphene for different applications: State-of-the-art. Surfaces and Interfaces 2017; 9: 93-106. https://doi.org/10.1016/j.surfin.2017.08.004

[37] Pumera M, Ambrosi A, Bonanni A, Chng ELK, Poh HL. Graphene for electrochemical sensing and biosensing. Trends Analyt Chem 2010; 29: 954-65. https://doi.org/10.1016/j.trac.2010.05.011

[38] Kaur G, Gupta S, Dharamvir K. Theoretical investigation of adsorption of gas molecules on $\mathrm{Li}$ metal adsorbed at $\mathrm{H}$-site of graphene: A search for graphene based gas sensors. Surfaces and Interfaces 2017; 8: 83-90.

https://doi.org/10.1016/i.surfin.2017.05.002

[39] Schedin F, Geim AK, Morozov SV, et al. Detection of individual gas molecules adsorbed on graphene. Nat Mater 2007; 6: 652-5. https://doi.org/10.1038/nmat1967

[40] Phiri J, Gane P, Maloney TC. General overview of graphene: Production, properties and application in polymer composites. Mater Sci Eng B Solid State Mater Adv Technol 2017; 215: 9-28. https://doi.org/10.1016/i.mseb.2016.10.004

[41] Geim AK, Novoselov KS. The rise of graphene. Nat Mater 2007; 6 : 183-91. https://doi.org/10.1038/nmat1849 
[42] Chen X, Wu G, Jiang Y, Wang Y, Chen X. Graphene and graphenebased nanomaterials: the promising materials for bright future of electroanalytical chemistry. Analyst 2011; 136: 4631-40.

https://doi.org/10.1039/c1an15661f

[43] Mattevi C, Kim H, Chhowalla M. A review of chemical vapour deposition of graphene on copper. J Mater Chem 2011; 21: 3324-34. https://doi.org/10.1039/C0JM02126A

[44] Kim KS, Zhao $\mathrm{Y}$, Jang $\mathrm{H}$, et al. Large-scale pattern growth of graphene films for stretchable transparent electrodes. Nature 2009; 457: 706-10.

https://doi.org/10.1038/nature07719

[45] Li X, Cai W, An J, Kim S, Nah J, Yang D, et al. Large-Area Synthesis of High-Quality and Uniform Graphene Films on Copper Foils. Science 2009; 324: 1312-4. https://doi.org/10.1126/science. 1171245

[46] Nam J, Kim DC, Yun H, et al. Chemical vapor deposition of graphene on platinum: Growth and substrate interaction. Carbon N Y 2017; 111: 733-40.

https://doi.org/10.1016/j.carbon.2016.10.048

[47] Geim AK. Graphene: status and prospects. Prospects 2009; 324: 1-8. https://doi.org/10.1126/science. 1158877

[48] $\mathrm{Mu} \mathrm{W}, \mathrm{Fu} \mathrm{Y}$, Sun S, et al. Controllable and fast synthesis of bilayer graphene by chemical vapor deposition on copper foil using a cold wall reactor. Chem Eng J 2016; 304: 106-14.

https://doi.org/10.1016/i.cej.2016.05.144

[49] Zhang Y, Chen Y, Zhou K, Liu C. Improving gas sensing properties of graphene by introducing dopants and defects : a first-principles study. Nanotechnology 2009; 20: 1-8. https://doi.org/10.1088/0957-4484/20/18/185504

[50] Nayak PK, Wang Z, Hedhili MN, Wang QX, Alshareef HN. Semiconductor (CMOS) Device Using a Single-Step Deposition of the Channel Layer. Sci Rep 2014; 4: 1-7. https://doi.org/10.1038/srep04672

[51] Cadore AR, Mania E, Alencar AB, et al. Enhancing the response of $\mathrm{NH} 3$ graphene-sensors by using devices with different graphenesubstrate distances. Sens Actuators B Chem 2018; 1-19. https://doi.org/10.1016/j.snb.2018.03.164

[52] Axet MR, Bacsa RR, Machado BF, Serp P. Adsorption on and reactivity of carbon nanotubes and graphene. In: Kadish K, D'souza F, editors. Handbook of Carbon Nano Materials. World Scientific 2014 ; p. 39-183. https://doi.org/10.1142/9789814566704_0002

[53] Aroutiounian V. Band Gap Opening in Graphene. Armen J Phys 2013; 6: $141-8$
[54] Varghese SS, Varghese SH, Swaminathan S, Singh KK, Mittal V. Two-Dimensional Materials for Sensing: Graphene and Beyond. Electronics 2015; 4: 651-87.

https://doi.org/10.3390/electronics4030651

[55] Knez M, Nielsch K, Niinistö L. Synthesis and surface engineering of complex nanostructures by atomic layer deposition. Adv Mater 2007; 19: $3425-38$ https://doi.org/10.1002/adma.200700079

[56] Marichy C, Pinna N. Carbon-nanostructures coated/decorated by atomic layer deposition: Growth and applications. Coord Chem Rev 2013; 257: 3232-53. https://doi.org/10.1016/i.ccr.2013.08.007

[57] George SM. Atomic Layer Deposition: An Overview. Chem Rev 2010 110: 111- 31 https://doi.org/10.1021/cr900056b

[58] Elam JW, Groner MD, George SM. Viscous flow reactor with quartz crystal microbalance for thin film growth by atomic layer deposition. Rev Sci Instrum 2013; 73: 2981-7. https://doi.org/10.1063/1.1490410

[59] Meng X, Byun Y, Kim HS, et al. Atomic Layer Deposition of Silicon Nitride Thin Films: A Review of Recent Progress, Challenges, and Outlooks. Materials (Basel) 2016; 9: 1-20. https://doi.org/10.3390/ma9121007

[60] Kim H, Lee HBR, Maeng WJ. Applications of atomic layer deposition to nanofabrication and emerging nanodevices. Thin Solid Films 2009; 517: 2563-80 https://doi.org/10.1016/j.tsf.2008.09.007

[61] Neri G, Bonavita A, Rizzo G, et al. Towards enhanced performances in gas sensing: $\mathrm{SnO} 2$ based nanocrystalline oxides application. Sens Actuators B Chem 2007; 122: 564-71. https://doi.org/10.1016/i.snb.2006.07.006

[62] Gopel W, Schierbaum K. SNO2 sensors: current status and future prospects. Sens Actuators B Chem. 1995; 27: 1-12. https://doi.org/10.1016/0925-4005(94)01546-T

[63] Ferrari AC, Basko DM. Raman spectroscopy as a versatile tool for studying the properties of graphene. Nat Nanotechnol 2013; 8: 235 46.

https://doi.org/10.1038/nnano.2013.46

[64] Nayak P, Caraveo-Frescas J, Wang Z, et al. Thin Film Complementary Metal Oxide Semiconductor (CMOS) Device Using a Single-Step Deposition of the Channel Layer. Sci Rep 2014; 4: 1-7. https://doi.org/10.1038/srep04672 